\title{
Chronic valvular disease: correlation between clinical, electrocardiographic, radiographic and echocardiographic aspects in dogs
}

\author{
[Doença valvar crônica: correlação entre aspectos clínicos, eletrocardiográficos, \\ radiográficos e ecocardiográficos em cães] \\ E.C. Soares, M.H.M.A. Larsson*, R.J. Yamato \\ Faculdade de Medicina Veterinária e Zootecnia - Universidade de São Paulo \\ Avenida Ceci, 543- Planalto Paulista \\ 04065-000 - São Paulo, SP
}

\begin{abstract}
Echocardiographic aspects of chronic mitral valvular disease were studied and compared to physical, radiographic and electrocardiographic aspects. Seventy dogs were used, and clinical examination, thoracic radiography, electrocardiogram and echocardiogram were performed. Correlations between regurgitation severity with cardiac failure functional class and murmur intensity were observed. The electrocardiogram showed a low sensibility in detecting cardiac chamber enlargement, caused by mitral regurgitation. All the dogs with severe mitral regurgitation showed cardiomegaly according to thoracic radiographies.
\end{abstract}

Keywords: dog, heart, cardiac failure, echocardiography, cardiac valve

\section{RESUMO}

Avaliaram-se os aspectos ecocardiográficos da doença valvar crônica, comparando-os com os aspectos clínicos, radiográficos e eletrocardiográficos em cães. Estudaram-se 70 animais, realizando-se exames físicos, radiografias torácicas, eletrocardiograma e ecocardiograma. Observaram-se correlações entre a gravidade da regurgitação, a classe funcional da insuficiência cardíaca e a intensidade de sopro. $O$ eletrocardiograma mostrou baixa sensibilidade para detectar aumento de câmaras cardíacas causadas por regurgitação mitral. Todos os cães com regurgitação mitral grave apresentaram cardiomegalia nas radiografias torácicas

Palavras-chave: cão, coração, insuficiência cardíaca, ecocardiografia, valva cardíaca

\section{INTRODUCTION}

The echocardiography is considered a new diagnostic method in veterinary medicine but definitely it is the most useful subsidiary exam in mitral chronic valvular disease (CVD). It provides information about the valvular lesion, regurgitation severity, and cardiac chambers size.
In CVD, the valvular lesion often is seen as leaflets thickening, and sometimes chordae tendinae rupture can occur. Also, left atrial and ventricular enlargement, free wall and septum hypertrophy, and/or increased shortening fraction can be observed (Boon, 1998).

Apoio financeiro: FAPESP

Recebido para publicação em 14 de abril de 2004

Recebido para publicação, após modificações, em 11 de

fevereiro de 2005

* Autor para correspondência (corresponding author)

E-mail: akaolar@usp.br 
The hemodynamic consequences of mitral insufficiency can be roughly evaluated by left atrial and ventricular chamber enlargement. When medium and large regurgitant jets occur, these chambers appear enlarged, secondary to volumetric overload. However, the enlargement of left chamber can be a good indication of the regurgitation severity just when atrial fibrilation or acute insufficiency do not occur (Morcerf, 1996).

According to Amberger et al. (1995), the aortic root to left atrial ratio, which has been used to evaluate atrial size, decreases as mitral regurgitation increases, but authors did not consider such cases as atrial fibrilation or acute insufficiency.

Pedersen (2000) considers the left atrium and ventricle size as a good indicator of mitral insufficiency, but he remarked that these measures have a large variation, even in dogs of similar body weight. Moreover, it was observed that an animal which presented mitral insufficiency for a period of five years, as example, showed the left atrium larger than the other that presented mitral regurgitation for a shorter period of time.

Despite the controversies, the Doppler echo is the best method in order to evaluate the regurgitation severity of mitral insufficiency. The pulsed wave (PW) Doppler allows classifying the regurgitation severity into mild, moderate or severe, in accordance to flow characteristics, as well as the area of left atrium the jet occupies. However, this method is quite old and it was replaced by color flow in the $80 \mathrm{~s}$. The color flow or color Doppler is much more efficient and practical. Several studies have been done in order to find a correlation between regurgitation degree and New York Heart Association/International Small Animal Cardiac Health Council (NYHA/ISACHC) heart failure functional class, murmur intensity and electrocardiographic and radiographic findings and different results have been achieved (Häggström et al., 1995; Pedersen et al., 1999).

The goal of this study was to compare the severity of regurgitation on echo to clinical aspects, as ISACHC heart failure functional class and murmur intensity, as well as to electrocardiographic and radiographic findings.

\section{MATERIALS AND METHODS}

Seventy mongrels and purebred, male and female dogs, at different ages, were presented to a cardiology service, showing signs related to cardiac failure or just murmurs at cardiac auscultation.

Questions concerning about cardiac failure symptoms were made and the obtained data were joined to the findings of clinical examination and subsidiary exams in order to pool the animals into groups according to the ISACHC cardiac failure classification.

Cardiac auscultation was performed and that allowed classifying the murmurs according to the 1 to 6 scale (Darke et al., 1996).

The radiographic examination of thorax was performed by radiodiagnosis device, CGR, $300 \mathrm{~mA}, 125 \mathrm{kV}, \mathrm{CH} 3000$ model. The radiographic evaluation was made by the vertebral heart size method described by Buchanan and Bücheler (1995).

Electrocardiographic exams of the animals were performed in right lateral recumbence, recording the bipolar standard leads, I, II and III, the augmented unipolar limb leads, aVR, aVL, aVF, and unipolar precordial chest leads, CV5RL (rV2), CV6LU (V2), CV6LL (V4) and V10 (Edwards, 1991; Tilley, 1992).

The echocardiographic exams were performed by a Hitachi echocardiography device, model EUB-515A, provided with pulsed-wave, continuous-wave, and color-flow Doppler, and a 3.5 or 5.0 MHZ transducer. The dogs were positioned over a proper table, on lateral recumbence, according to Pipers et al. (1991). The technique and interpretation of the exams agreed to Thomas (1984), Morcerf (1996) and Boon (1998).

$M$ mode measurements included: aorta diameter (Ao) measured in the beginning of the systole, left atrium diameter (LA) measured in the end of the systole, left ventricle diameter in diastole (LVDd), left ventricle diameter in systole (LVDs) and fractional shortening (FS) $(\mathrm{FS} \%)=\frac{\text { LVDd }- \text { LVDs }}{\text { LVDd }}$. 
Doppler (PW and color flow) was used to evaluate the regurgitation degree semiquantitatively. The method was that which compares the area of the regurgitant jet to the total area of the left atrium (Boon, 1998). So, when the jet occupied less the $20 \%$ of the left atrium, a discrete mitral insufficiency was considered. If it ranged from 20 to $50 \%$, it would be classified as moderate and if it reached more than $50 \%$ of the left atrium area, important mitral insufficiency would be considered.

\section{RESULTS}

The Tables 1, 2, 3, 4 and 5 show $M$ mode measurements and mitral regurgitation intensity of dogs classified as IA, IB, II, IIIA and IIIB, respectively.

The comparisons among clinical, electrocardiographic, radiographic and echocardiographic findings are showed in Tables $6,7,8$ and 9 .

Data on Table 6 compare echocardiographic findings to cardiac failure functional class. They reveal that five $(62.5 \%)$ out of eight animals included in IA functional class (asymptomatic patient; heart disease detectable by cardiac murmur, arrhythmia or cardiac enlargement, detected by radiography or echocardiography, but without overload volume or pressure ventricular hypertrophy), showed mild regurgitation on echocardiography and the other three dogs showed moderate insufficiency. Among dogs included in IB functional class (asymptomatic patient, with signs of cardiac disease and overload volume or pressure hypertrophy), $37.5 \%$ showed mild regurgitation, while the same percentage had moderate, and $25.0 \%$ had severe mitral regurgitation.

By taking FCIII dogs into account it was observed that among those included in IIIA functional class, six $(75.0 \%)$ revealed severe and two $(25.0 \%)$ moderate insufficiency, while dogs in CFIIIB showed severe mitral regurgitation.

Dogs classified as FCII revealed mild (38.1\%) and moderate $(40.4 \%)$ mitral regurgitation in most cases. Only $21.5 \%$ showed severe insufficiency.

Data on Table 7 compare echocardiographic findings to murmur intensity and show that most dogs which had low intensity murmurs revealed mild mitral regurgitation on echocardiographic exam. Most dogs with grade 4 murmur intensity showed moderate insufficiency, and those with grade 5 or 6 murmur intensity showed mainly severe regurgitation.

Data on Table 8 compare echocardiographic and electrocardiographic findings, demonstrating that most dogs which showed mild regurgitation on echo $(83.3 \%)$ did not reveal electrocardiographic abnormalities. Out of those which revealed severe mitral regurgitation, $38.0 \%$ did not have electrocardiographic abnormalities that could suggest cardiac chambers enlargement.

Table 1. M mode measurements and mitral regurgitation intensity of eight dogs included in IA functional class

\begin{tabular}{lcccccc}
\hline Dog & Ao & LA & Ao/LA & LVDd & FS\% & MR \\
\hline 1 & 1.80 & 1.80 & 1.00 & 2.50 & 34.6 & discrete \\
2 & 2.40 & 2.90 & 0.83 & 4.70 & 38.2 & discrete \\
3 & 1.90 & 2.04 & 0.93 & 3.21 & 37.0 & moderate \\
4 & 1.35 & 1.95 & 0.69 & 2.52 & 52.3 & moderate \\
5 & 2.60 & 3.00 & 0.87 & 4.90 & 35.0 & discrete \\
6 & 1.50 & 2.40 & 0.62 & 3.30 & 30.0 & moderate \\
7 & 1.30 & 1.80 & 0.72 & 2.50 & 45.0 & discrete \\
8 & 1.90 & 1.90 & 1.00 & 3.70 & 43.0 & discrete \\
Mean & 1.84 & 2.22 & 0.83 & 3.42 & 39.4 & \\
\hline I:
\end{tabular}

IA: asymptomatic patient; heart disease is detectable by cardiac murmur, arrhythmia or cardiac enlargement that is detected by radiography or echocardiography, but without overload volume or pressure ventricular hypertrophy. Ao: aorta diameter; LA: left atrium diameter; Ao/LA: aorta/left atrium diameter relation; LVDd: left ventricle diameter in diastole; FS: fractional shortening; MR: mitral regurgitation intensity.

Table 2. M mode measurements and mitral regurgitation intensity of eight dogs included in IB functional class

\begin{tabular}{lcccccc}
\hline Dog & Ao & LA & Ao/LA & LVDd & FS\% & MR \\
\hline 1 & 1.80 & 2.40 & 0.75 & 3.17 & 33.7 & moderate \\
2 & 1.40 & 2.50 & 0.56 & 3.10 & 40.0 & moderate \\
3 & 1.40 & 1.80 & 0.78 & 2.90 & 39.7 & moderate \\
4 & 1.70 & 2.70 & 0.63 & 3.70 & 41.1 & important \\
5 & 1.30 & 1.70 & 0.76 & 2.40 & 47.0 & discrete \\
6 & 1.50 & 2.50 & 0.60 & 3.12 & 42.6 & important \\
7 & 1.50 & 2.00 & 0.75 & 3.50 & 35.6 & discrete \\
8 & 1.66 & 1.85 & 0.90 & 2.85 & 47.0 & discrete \\
Mean & 1.53 & 2.18 & 0.72 & 3.09 & 40.8 & \\
\hline \multicolumn{7}{l}{ IB: asymptomatic patient, with signs of cardiac disease and } \\
overload volume or & pressure hypertrophy. Ao: aorta \\
diameter; LA: left atrium diameter; Ao/LA: aorta/left atrium \\
diameter relation; LVDd: left ventricle diameter in diastole; \\
FS: fractional shortening; MR: mitral regurgitation intensity.
\end{tabular}


Table 3. M mode measurements and mitral regurgitation intensity of $42 \mathrm{dogs}$ included in functional class

\begin{tabular}{|c|c|c|c|c|c|c|}
\hline Dog & Ao & LA & Ao/LA & LVDd & $\mathrm{FS} \%$ & MR \\
\hline 1 & 1.60 & 1.60 & 1.00 & 2.60 & 45.0 & discrete \\
\hline 2 & 1.80 & 1.80 & 1.00 & 3.20 & 46.0 & discrete \\
\hline 3 & 1.35 & 1.45 & 0.90 & 1.84 & 45.1 & discrete \\
\hline 4 & 2.53 & 2.61 & 0.97 & 3.22 & 41.9 & discrete \\
\hline 5 & 1.20 & 2.10 & 0.57 & 2.30 & 50.0 & important \\
\hline 6 & 1.46 & 1.84 & 0.79 & 2.80 & 35.7 & moderate \\
\hline 7 & 1.80 & 3.30 & 0.54 & 4.10 & 48.0 & important \\
\hline 8 & 1.60 & 3.30 & 0.48 & 4.30 & 42.0 & important \\
\hline 9 & 1.40 & 1.70 & 0.82 & 2.90 & 42.5 & moderate \\
\hline 10 & 1.60 & 1.90 & 0.84 & 2.90 & 50.8 & discrete \\
\hline 11 & 1.90 & 2.30 & 0.83 & 3.00 & 31.4 & discrete \\
\hline 12 & 2.20 & 3.50 & 0.63 & 4.20 & 38.0 & moderate \\
\hline 13 & 1.90 & 2.70 & 0.70 & 4.10 & 31.4 & discrete \\
\hline 14 & 1.90 & 2.10 & 0.90 & 3.50 & 44.2 & moderate \\
\hline 15 & 1.70 & 2.70 & 0.63 & 3.60 & 43.1 & important \\
\hline 16 & 1.40 & 2.50 & 0.56 & 3.85 & 45.4 & important \\
\hline 17 & 1.50 & 1.70 & 0.88 & 2.50 & 37.0 & discrete \\
\hline 18 & 1.85 & 2.00 & 0.92 & 3.30 & 43.4 & discrete \\
\hline 19 & 1.60 & 2.60 & 0.61 & 3.20 & 45.0 & important \\
\hline 20 & 1.40 & 2.00 & 0.70 & 3.00 & 51.0 & moderate \\
\hline 21 & 2.20 & 2.90 & 0.76 & 5.30 & 50.0 & moderate \\
\hline 22 & 1.40 & 1.90 & 0.74 & 3.30 & 30.0 & moderate \\
\hline 23 & 1.51 & 1.73 & 0.87 & 2.34 & 50.4 & discrete \\
\hline 24 & 2.00 & 2.90 & 0.69 & 4.40 & 49.3 & important \\
\hline 25 & 1.60 & 1.80 & 0.89 & 2.87 & 34.1 & moderate \\
\hline 26 & 1.20 & 1.40 & 0.86 & 2.60 & 47.3 & moderate \\
\hline 27 & 1.70 & 3.10 & 0.55 & 4.10 & 46.0 & important \\
\hline 28 & 2.15 & 2.15 & 1.00 & 3.50 & 32.0 & moderate \\
\hline 29 & 1.00 & 1.00 & 1.00 & 2.80 & 46.0 & moderate \\
\hline 30 & 2.30 & 2.60 & 0.88 & 4.10 & 42.6 & discrete \\
\hline 31 & 1.60 & 1.70 & 0.94 & 2.50 & 42.0 & discrete \\
\hline 32 & 1.55 & 1.98 & 0.78 & 2.70 & 39.0 & discrete \\
\hline 33 & 2,64 & 3.36 & 0.78 & 5.17 & 44.1 & moderate \\
\hline 34 & 2.30 & 3.70 & 0.62 & 6.00 & 34.2 & important \\
\hline 35 & 1.80 & 2.80 & 0.64 & 3.30 & 45.0 & discrete \\
\hline 36 & 1.90 & 2.70 & 0.70 & 3.90 & 38.4 & moderate \\
\hline 37 & 1.80 & 2.20 & 0.82 & 2.90 & 43.0 & discrete \\
\hline 38 & 1.70 & 2.10 & 0.81 & 3.20 & 50.0 & discrete \\
\hline 39 & 1.53 & 2.30 & 0.66 & 3.06 & 33.9 & moderate \\
\hline 40 & 1.60 & 2.30 & 0.69 & 2.50 & 52.0 & moderate \\
\hline 41 & 1.30 & 1.80 & 0.72 & 1.20 & 54.7 & moderate \\
\hline 42 & 1.20 & 1.30 & 0.92 & 2.15 & 63.7 & moderate \\
\hline Mean & 1.71 & 2.27 & 0.78 & 3.29 & 43.4 & \\
\hline
\end{tabular}

II: mild to moderate cardiac failure. Ao: aorta diameter; LA: left atrium diameter; Ao/LA: aorta/left atrium diameter relation; LVDd: left ventricle diameter in diastole; FS: fractional shortening; MR: mitral regurgitation intensity.
Table 4. M mode measurements and mitral regurgitation intensity of eight dogs included in IIIA functional class

\begin{tabular}{lcccccc}
\hline Dog & Ao & LA & Ao/LA & LVDd & FS\% & MR \\
\hline 1 & 1.4 & 1.90 & 0.74 & 2.9 & 42.0 & moderate \\
2 & 1.60 & 2.70 & 0.59 & 2.6 & 42.0 & important \\
3 & 1.50 & 2.64 & 0.57 & 3.7 & 43.2 & important \\
4 & 1.50 & 3.70 & 0.40 & 5.2 & 49.0 & important \\
5 & 2.20 & 3.40 & 0.64 & 4.8 & 43.1 & moderate \\
6 & 1.70 & 3.10 & 0.55 & 3.9 & 46.0 & important \\
7 & 1.47 & 2.93 & 0.50 & 4.3 & 44.0 & important \\
8 & 1.40 & 2.70 & 0.52 & 3.6 & 45.9 & important \\
Mean & 1.60 & 2.88 & 0.55 & 3.9 & 44.4 & \\
\hline
\end{tabular}

IIIA: advanced cardiac failure; home possible care. Ao: aorta diameter; LA: left atrium diameter; Ao/LA: aorta/left atrium diameter relation; LVDd: left ventricle diameter in diastole; FS: fractional shortening; MR: mitral regurgitation intensity.

Table 5. M mode measurements and mitral regurgitation intensity of four dogs included in IIIB functional class

\begin{tabular}{lcccccc}
\hline Dog & Ao & LA & Ao/LA & LVDd & FS\% & MR \\
\hline 1 & 2.00 & 5.00 & 0.40 & 5.0 & 30.0 & important \\
2 & 1.57 & 3.36 & 0.47 & 4.5 & 48.1 & important \\
3 & 1.30 & 2.00 & 0.65 & 3.3 & 38.1 & important \\
4 & 1.20 & 2.40 & 0.50 & 3.2 & 49.0 & important \\
Mean & 1.52 & 3.19 & 0.50 & 4.0 & 41.3 & \\
\hline
\end{tabular}

IIIB: advanced cardiac failure; hospitalization mandatory. Ao: aorta diameter; LA: left atrium diameter; Ao/LA: aorta/left atrium diameter relation; LVDd: left ventricle diameter in diastole; FS: fractional shortening; MR: mitral regurgitation intensity.

Table 6. Distribution of 70 chronic valvular disease cases, according to functional class and echocardiographic findings, presented to cardiology service

\begin{tabular}{lcccc}
\hline \multirow{2}{*}{ FC } & \multicolumn{3}{c}{ ECHO } \\
\cline { 3 - 5 } & & Mild MR & Moderate MR & Severe MR \\
\hline \multirow{2}{*}{ I } & IA (N=8) & $62.5 \%$ & $37.5 \%$ & - \\
\multirow{2}{*}{ II } & IB (N=8) & $37.5 \%$ & $37.5 \%$ & $25.0 \%$ \\
\multirow{2}{*}{ III } & IIIA (N=8) & $38.1 \%$ & $40.4 \%$ & $21.5 \%$ \\
\cline { 3 - 5 } & IIIB (N=4) & - & $25.0 \%$ & $75.0 \%$ \\
ICC & & - & - & $100 \%$ \\
\hline
\end{tabular}

$\overline{\mathrm{FC}}=$ cardiac failure functional class: IA - asymptomatic patient; heart disease is detectable by cardiac murmur, arrhythmia or cardiac enlargement that is detected by radiography or echocardiography, but without overload volume or pressure ventricular hypertrophy. IB asymptomatic patient; with signs of cardiac disease and overload volume or pressure hypertrophy. II - mild to moderate cardiac failure; IIIA - advanced cardiac failure; home care possible; IIIB - advanced cardiac failure; hospitalization mandatory. ECHO: echocardiographic findings; MR: mitral regurgitation. 
Table 7. Distribution of 70 chronic valvular disease cases, according to murmur intensity and echocardiographic findings, presented to cardiology service

\begin{tabular}{|c|c|c|c|}
\hline \multirow{2}{*}{ MI } & \multicolumn{3}{|c|}{ ECHO } \\
\hline & Mild MR & Moderate MR & Severe MR \\
\hline grade $1(n=3)$ & $100 \%$ & - & - \\
\hline $\operatorname{grade} 2(n=3)$ & $66.7 \%$ & $33.3 \%$ & - \\
\hline grade $3(n=17)$ & $58.8 \%$ & $35.3 \%$ & $5.9 \%$ \\
\hline $\operatorname{grade} 4(n=28)$ & $32.0 \%$ & $46.0 \%$ & $22.0 \%$ \\
\hline grade $5(n=15)$ & - & $26.7 \%$ & $73.3 \%$ \\
\hline grade $6(n=4)$ & - & $25.0 \%$ & $75.0 \%$ \\
\hline
\end{tabular}

Data on Table 9, comparing echocardiographic to radiographic findings, reveal that most dogs with mild mitral regurgitation did not have radiographic abnormalities on cardiac silhouette. On the other hand, dogs with moderate or severe mitral regurgitation showed $60.0 \%$ or $85.7 \%$ of cardiomegaly on thoracic radiographies.

Some rhythm disturbances were detected, as supraventricular premature complexes in four dogs $(5.7 \%)$, ventricular premature complexes in four dogs $(5.7 \%)$, sinoatrial blockade in four dogs $(5.7 \%)$, atrioventricular blockade in two dogs $(2.9 \%)$ and right bundle blockade in two dogs $(2.9 \%)$.

Table 8. Distribution of 70 chronic valvular disease cases, according to echocardiographic and electrocardiographic findings, presented to cardiology service

\begin{tabular}{|c|c|c|c|c|c|c|c|c|c|c|}
\hline \multirow[b]{2}{*}{ ECHO } & \multicolumn{10}{|c|}{ ECG } \\
\hline & LAE & RAE & LVE & RVE & BAE & RAE & LAE & BAE & BAE & NA \\
\hline Mild MR $(n=24)$ & - & - & $8.3 \%$ & $4.2 \%$ & - & - & $4.2 \%$ & - & - & $83.3 \%$ \\
\hline Moderate MR $(n=25)$ & $8.0 \%$ & $8.0 \%$ & $28.0 \%$ & - & $4.0 \%$ & $4.0 \%$ & $4.0 \%$ & - & - & $44.0 \%$ \\
\hline Severe MR $(n=21)$ & $9.5 \%$ & - & $14.4 \%$ & - & $4.8 \%$ & $9.5 \%$ & $9.5 \%$ & $9.5 \%$ & $4.8 \%$ & $38.0 \%$ \\
\hline
\end{tabular}

ECHO: echocardiographic findings; MR: mitral regurgitation. ECG: electrocardiographic findings; LAE: left atrium enlargement; RAE: right atrium enlargement; LVE: left ventricle enlargement; RVE: right ventricle enlargement; BAE: biatrial enlargement; BE: biventricular enlargement; NA: no abnormalities.

Table 9. Distribution of 70 chronic valvular disease cases, according to echocardiographic and radiographic findings, presented to cardiology service

\begin{tabular}{|c|c|c|}
\hline \multirow{2}{*}{ ECHO } & $\mathrm{XR}$ & \\
\hline & cardiomegaly & normal \\
\hline Mild MR ( $\mathrm{n}=24)$ & $20.8 \%$ & $79.2 \%$ \\
\hline Moderate MR $(n=25)$ & $60.0 \%$ & $40.0 \%$ \\
\hline Severe MR $(n=21)$ & $85.7 \%$ & $14.3 \%$ \\
\hline
\end{tabular}

\section{DISCUSSION}

By comparing the heart failure classification with the regurgitation severity, it was observed that the degree of regurgitation correlates very well with the severity of heart failure.

Amberger et al. (1995) compared echocardiographic findings with cardiac failure classification. According to this study, $100 \%$ of dogs included in class IV (NYHA), or advanced cardiac failure, showed LA/Ao ratio $>1$, which means that all animals had left atrium enlargement.

Boon (1998) referred that stages 3 and 4 of the NYHA criteria for dogs' atrial size were significantly larger than the stage 2 , while stage 2 failure were significantly larger than the atrial of dogs with no heart failure or stage 1 heart failure. Uehara and Takahashi (1996), by measuring the mitral regurgitation by the ratio of color flow mapping area of mitral regurgitant jet/aortic forward flow mapping area, demonstrated that this ratio increases as cardiac failure worse.

By comparing murmur intensity to mitral regurgitation severity (Table 7), it was observed that the regurgitation severity also correlates with the murmur intensity. Opposite to these findings, Amberger et al. (1995) claimed that the murmur intensity is not a good indication of regurgitation hemodynamic severity. Yet, Sisson and Ettinger (1999) referred that high intensity murmurs originate in narrow orifices, with small regurgitant jets. As the disease advances, 
murmur intensity declines, because pressure difference between ventricle and atrium decreases. Braunwald (1997) also described a negative correlation between these characteristics. Tribouilloy et al. (1986) referred that auscultation has a sensibility of just $74.5 \%$ to detect regurgitant flows. On the other hand, Häggström et al. (1995) studied Cavalier King Charles Spaniels and observed that dogs which had high intensity murmurs revealed left ventricle diastolic diameter and LA/Ao ratio higher than dogs which presented moderate intensity murmurs, and these had chambers size higher than those which had low intensity murmurs. Pedersen (2000) and Pedersen et al. (1999) stated that murmur intensity increases with regurgitation severity, evaluated by color flow Doppler.

The Table 8 shows that the electrocardiographic exam is not a reliable diagnostic method to evaluate CVD hemodynamic consequences, mainly due to its low sensibility. However, it can be observed that all cases that the electrocardiographic recordings pointed to left atrial enlargement revealed left atrium dilation on echo, and this meant a good predictive value, similarly to the electrocardiogram low sensibility observed by Lombard and Spencer (1985).

Finally, data on Table 4 show a good association between regurgitation severity and radiographic findings; cardiomegaly was observed mainly in cases of severe valve insufficiency. The same was found by Lombard and Spencer (1985). The false positives cases can be due to the subjective radiographic criteria for left atrial enlargement, which may overestimate the size of cardiac chambers.

\section{REFERENCES}

AMBERGER, C.; GLARDON, O.; LOMBARD, C.W. Validité des examens complementaires dans l'evaluation de l'insuffisance cardiaque par endocardiose mitrale. Étude a partir de 106 cas. Pratiq. Med. Chirurg. Anim. Comp., v.30, p.659-670, 1995.

BOON, J.A. Acquired heart disease. In: MANUAL of veterinary echocardiography. Baltimore: Williams \& Wilkins, 1998. cap. 4, p.261-382.

BRAUNWALD, E. Valvulopatias. In: BRAUNWALD, E. Tratado de medicina cardiovascular. 5.ed. São Paulo:
Roca, 1997. p.1075-1148.

BUCHANAN, J.W.; BÜCHELER, J. Vertebral scale system to measure canine heart size im radiographs. $J$. Am. Vet. Med. Assoc., v.206, p.194-199, 1995.

DARKE, P.G.G.; BONAGURA, J.D; KELLY, D.F. Color atlas of veterinary cardiology. London: MosbyWolfe, 1996. 186p.

EDWARDS, N. J. Bolton's handbook of canine and feline electrocardiography. 2.ed. Philadelphia: W.B. Saunders, 1991. 381p.

HÄGGSTRÖM, J.; KVART, C.; HANSSON, K. Heart sounds and murmurs: changes related to severity of chronic valvular disease in the Cavalier King Charles Spaniel. J. Vet. Int. Med., v.9, p.75-85, 1995.

LOMBARD, C.W.; SPENCER, C.P. Correlation of radiographic, echocardiographic and electrocardiographic signs of left heart enlargemente in dogs with mitral regurgitation. Vet. Radiol., v.26, p.89-97, 1985.

MORCERF, F.A. Ecocardiografia. 2.ed. Rio de Janeiro:Revinter, 1996. 671p.

PEDERSEN, H.D. Diagnóstico de la enfermedad de la válvula mitral mixomatosa canina. Waltham Focus, v.10, p.3-9, 2000.

PEDERSEN, H.D.; HÄGGSTRÖM, J.; FALK, T. et al. Auscultation in mild regurgitation in dogs: observer variation, effects o physical maneuvers, and agreement with color Doppler echocardiography and phonocardiography. J. Vet. Int. Med., v.13, p.56-64, 1999.

PIPERS, F.S.; BONAGURA, J.D.; HAMLIN, R.L. et al. Echocardiographic abnormalities of the mitral valve associated with left-side heart diseases in the dog. J. Am. Vet. Med. Assoc., v.179, p.580-586, 1991.

SISSON, D.; ETTINGER, S.J. The physical examination. In: FOX, P.R.; SISSON, D.; MOISE, N.S. Textbook of canine and feline cardiology. 2.ed. Philadelphia: W.B Saunders, 1999. cap.2, p.46-64.

THOMAS, W.P. Two-dimensional, real time echocardiography in the dog: technique and anatomic validation. Vet. Radiol., v.25, p.50-64, 1984.

TILLEY, P.T. Essentials of canine and feline electrocardiography. 3.ed. Philadelphia: Lea \& Febiger, 1992. 470p.

TRIBOUILLOY, C.; CASIER, B.; VOVAN, A. et al. Apport du Doppler pulsé et continu au qualitatif et quantitatif d'insuffisance mitrale. Arch. Mal. Coeur, v.76, p.473-481, 1986

UEHARA, Y.; TAKAHASHI, M. Quantitative evaluation of the severity of mitral insufficiency in dogs by the color Doppler method. J. Vet. Med. Sci., v.58, p.249-253, 1996. 